\title{
Did the Stock Market Regime Change after the Inauguration of the New Cabinet in Japan?
}

\author{
Chikashi Tsuji \\ Faculty of Economics, Chuo University \\ 742-1 Higashinakano Hachioji-shi, Tokyo 192-0393, Japan \\ E-mail: mail_sec_low@minos.ocn.ne.jp
}

Received: June 21, 2014 Accepted: June 26, 2014 Published: June 26, 2014

doi:10.5296/bmh.v2i1.5866 URL: http://dx.doi.org/10.5296/bmh.v2i1.5866

\begin{abstract}
This paper explored whether the Japanese stock market regime changed after the inauguration of the new Abe cabinet in Japan. Our application of Markov switching models to the Japanese stock price index returns and examinations of the price spreads in terms of the Japanese stock price indices derive the following evidence. First, (1) after the Abe cabinet started, regime of the Japanese stock markets changed. Second, (2) the regimes as to the JASDAQ Index and Tokyo Stock Exchange (TSE) Mothers Index more strongly and earlier changed than that of TOPIX. Third, (3) in our full sample period from January 4, 2011 to March 20, 2014, average positive price spreads over TOPIX were observed as to the JASDAQ, TSE Mothers, TOPIX Small, and TSE Second Section Index.
\end{abstract}

Keywords: JASDAQ Index, Markov switching model, TOPIX, TOPIX Core30 Index, TOPIX Large70 Index, TOPIX Small Index, TSE Mothers Index, TSE Second Section Index 


\section{Introduction}

On December 26, 2012, the new Abe cabinet was inaugurated in Japan. Did the Japanese stock market regimes changed after the inauguration of the new cabinet? In order to answer this question by the actual data, we analyze several Japanese stock market indices by using Markov switching models (e.g. Hamilton; 1989). Inquiring into the existing literature, many studies applied Markov switching models to economic or financial market data; however, because the Abe cabinet was inaugurated in December 2012, we check and review them by particularly focusing on recent papers that applied Markov switching models as below.

Terra and Valladares (2010) examined episodes as to the appreciations and depreciations of real exchange rates for 85 countries from 1960 to 1998. They used the two-regime Markov switching model in order to characterize real exchange rate misalignment series. Pardo et al. (2011) compared a deterministic model and a Markov switching model to investigate the behavior of the US economy and the Federal Reserve from 1960 to 2008. Pataracchia (2011) suggested a method to derive the spectral density function of Markov switching ARMA models and applied their method to the data of US economy. Tamgac (2011) investigated the role of fundamentals and expectations in the crisis episodes of Turkey. Analyzing the period from 1994 to 2001 by using a Markov switching framework, the study concluded that, for the Turkish currency crisis, not only the economic fundamentals but also the shifts in the devaluation expectations of agents had played a significant role.

Further, Guidolin and Hyde (2012) considered strategic asset allocation problems by comparing vector autoregression (VAR) approaches, which are standard in the field, and a Markov switching approach with bull and bear regimes. They concluded that most VAR approaches cannot approximate Markov switching asset allocation. Taamouti (2012) also considered the asset allocation problems applying a Markov switching framework to the monthly data of S\&P composite index, 10-year government bond, and three-month Treasury bill from January 1958 to December 2006.

Moreover, Chen (2013) analyzed the regime switching properties of the US current account deficits. They suggested that, when the empirical sample ends in the fourth quarter of 2008, the estimates from the Markov switching unit root regression obtained a reasonable two-state classification; however, when the sample is extended to the first quarter of 2009 or beyond, then the estimates from the above regression derived quite unreasonable results. Pan and Li (2013) proposed a Bayesian unit root testing approach for Markov switching stochastic volatility (MSSV) models and applied the developed approach to the S\&P 500 daily return data. As to the Japanese stock markets, Tsuji (2007) explored macroeconomic factors priced in the Japanese equity markets; however, this study did not use Markov switching models. Further, Tsuji (2012) analyzed the residual stock return premia derived from asset pricing models by using the two-regime Markov switching models; however, the focus of this study was not on the regime shifts after the new cabinet inauguration in Japan in December 2012.

As above, in the recent preceding studies, although Markov switching models were applied in various contexts, we cannot find the international academic study that examined the regime switching situation of the Japanese stock markets after the inauguration of the new Abe 
cabinet in Japan. Based on our above research motivation and the states of existing literature, this paper explores whether the Japanese stock market regimes changed after the inauguration of the new Abe cabinet in Japan. Our application of Markov switching models to the Japanese stock price index returns and examinations of the adjusted price spreads of the Japanese stock price indices clarify the following evidence. First, (1) after the Abe cabinet started, regime of the Japanese stock markets changed. Second, (2) the regimes as to the JASDAQ Index and Tokyo Stock Exchange (TSE) Mothers Index more strongly and earlier changed than that of TOPIX. Third, (3) in our full sample period from January 4, 2011 to March 20, 2014, average positive excess price spreads over TOPIX were observed as to the JASDAQ, TSE Mothers, TOPIX Small, and TSE Second Section Index. The rest of the paper is organized as follows. Section 2 explains our data, Section 3 describes our models, Section 4 documents our empirical results, and Section 5 presents our conclusion.

\section{Data}

This section explains our data analyzed in this paper. All data are provided by the QUICK Corp. In addition, our full sample period spans January 4, 2011 to March 20, 2014. In our analyses, we first use seven stock index return variables as follows: DLTOPIX denotes the first log difference of the daily closing price of TOPIX. This variable is computed as the percentage $\log$ return by multiplying 100 . In this study, we use the percentage log return for all variables as to the Japanese stock markets. Similarly, DLJAS represents the percentage log return calculated from the daily closing price of the JASDAQ Index; DLMO denotes the percentage log return of the TSE Mothers Index; DLCORE is that of the TOPIX Core30 Index; DLLARGE means that of the TOPIX Large70 Index; DLSMALL indicates that of the TOPIX Small Index; DLSEC denotes that of the TSE Second Section Index.

Further, we also use six variables of the adjusted stock index price spreads. In order to compute the price spreads, we first adjust the values of six indices and TOPIX so that their values become 100 on January 4, 2011, and then compute the six price spreads as follows: JASSP denotes the difference of the adjusted JASDAX Index value minus adjusted TOPIX value; MOSP is the difference of the adjusted TSE Mothers Index value minus adjusted TOPIX value; CORESP indicates the difference of the adjusted TOPIX Core30 Index value minus adjusted TOPIX value; LARGESP means the difference of the adjusted TOPIX Large70 Index value minus adjusted TOPIX value; SMALLSP represents the difference of the adjusted TOPIX Small Index value minus adjusted TOPIX value; SECSP denotes the difference of the adjusted TSE Second Section Index value minus adjusted TOPIX value.

Figure 1 displays the daily time-series evolution of the adjusted values of six stock price indices with the adjusted values of TOPIX. More concretely, Panel A displays the adjusted JASDAX Index values with the adjusted TOPIX values; Panel B shows the adjusted TSE Mothers Index values and the adjusted TOPIX values; Panel $\mathrm{C}$ exhibits the adjusted values of the TOPIX Core30 Index and those of TOPIX; Panel D indicates the adjusted values of TOPIX Large70 Index and those of TOPIX; Panel E shows the adjusted values of TOPIX Small Index values and those of TOPIX; Panel F displays the adjusted values of TSE Second Section Index and those of TOPIX. 
Panel A. JASDAQ

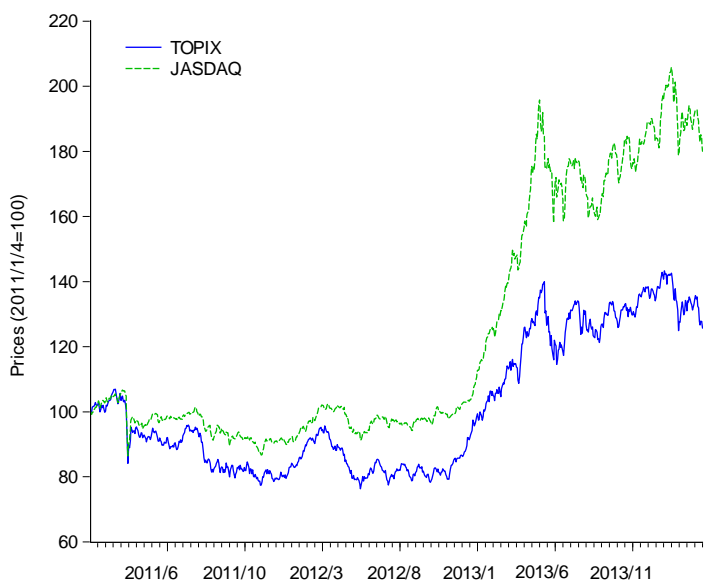

Panel C. TOPIX Core30

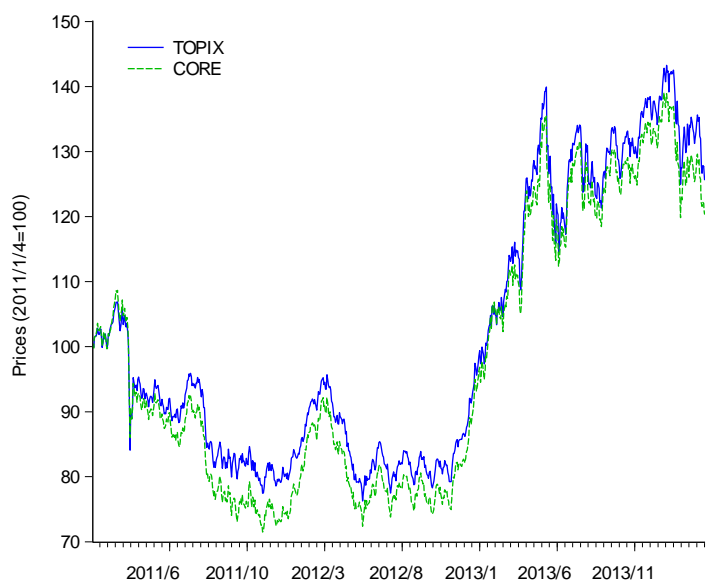

Panel E. TOPIX Small

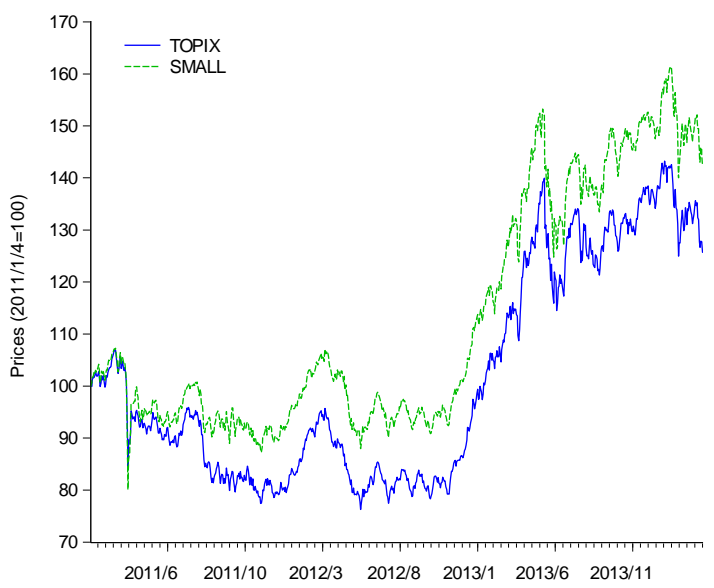

Panel B. TSE Mothers

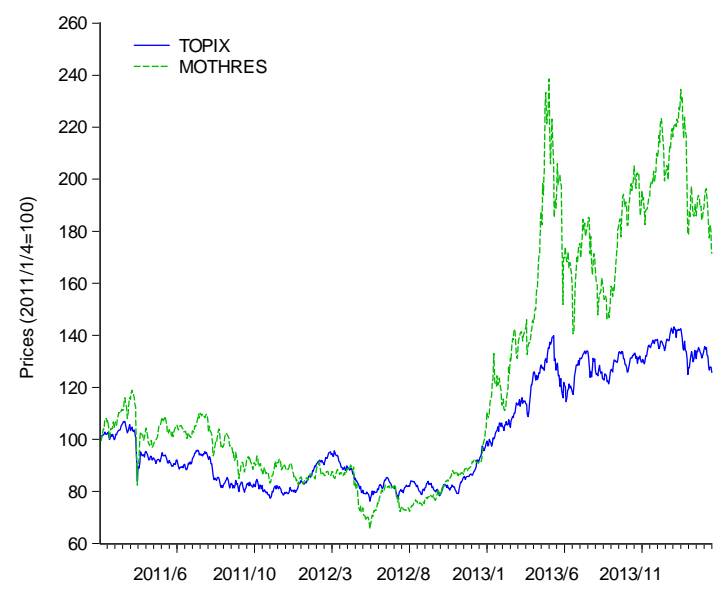

Panel D. TOPIX Large70

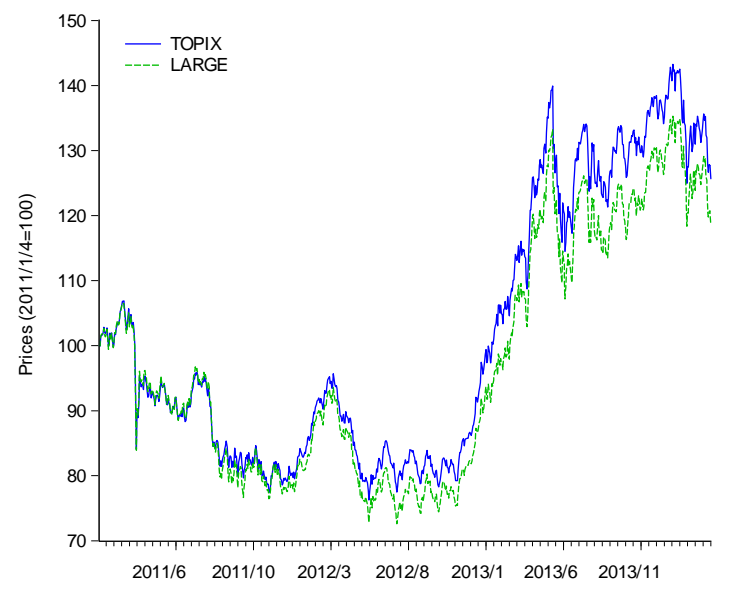

Panel F. TSE Second Section

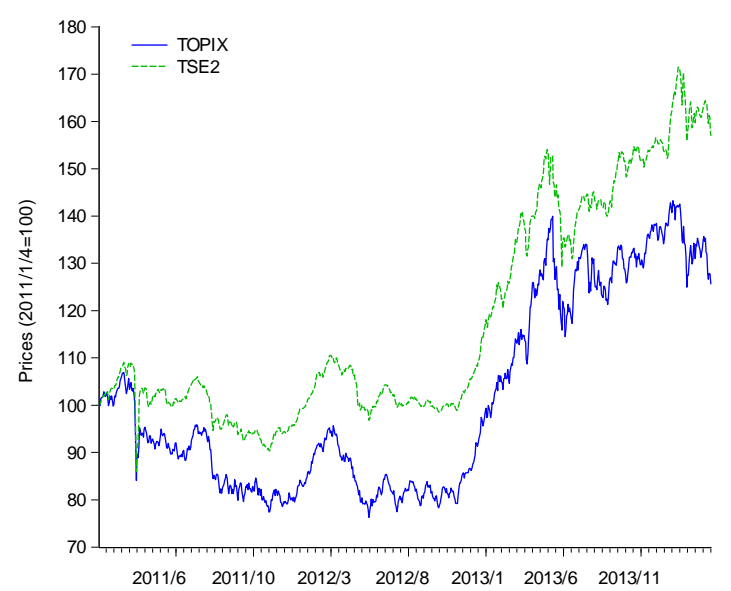

Figure 1. Dynamics of the adjusted values of the Japanese stock price indices: time-series comparison with TOPIX for the period from January 4, 2011 to March 20, 2014 
Table 1. Summary statistics for the daily $\log$ return and the adjusted price spreads: Descriptive statistics for the period from January 4, 2011 to March 20, 2014

Panel A. Statistics for the percentage log return

\begin{tabular}{|c|c|c|c|c|}
\hline & DLTOPIX & DLJAS & DLMO & DLCORE \\
\hline Mean & 0.0308 & 0.0752 & 0.0705 & 0.0252 \\
\hline Median & 0.0524 & 0.1236 & 0.2328 & -0.0293 \\
\hline Mean (annualized) & 7.7497 & 18.9590 & 17.7646 & 6.3468 \\
\hline Std. Dev. & 1.3558 & 1.1748 & 2.5433 & 1.4061 \\
\hline Skewness & -0.8336 & -1.8082 & -1.2925 & -0.4527 \\
\hline Kurtosis & 6.4025 & 14.8694 & 8.6279 & 3.2953 \\
\hline \multirow[t]{2}{*}{ Obs. } & 790 & 790 & 790 & 790 \\
\hline & DLLARGE & & DLSMALL & DLSEC \\
\hline Mean & 0.0238 & & 0.0470 & 0.0582 \\
\hline Median & 0.0622 & & 0.1172 & 0.1122 \\
\hline Mean (annualized) & 6.0031 & & 11.8379 & 14.6754 \\
\hline Std. Dev. & 1.4419 & & 1.3778 & 1.0042 \\
\hline Skewness & -0.6814 & & -1.6988 & -3.1158 \\
\hline Kurtosis & 5.0797 & & 16.5781 & 38.5562 \\
\hline Obs. & 790 & & 790 & 790 \\
\hline
\end{tabular}

Panel B. Statistics for the price spreads over the TOPIX

\begin{tabular}{llll}
\hline & JASSP & MOSP & CORESP \\
\hline Mean & 22.2522 & 20.5573 & -3.5963 \\
Median & 14.4484 & 10.1609 & -3.7703 \\
Std. Dev. & 18.2321 & 26.4318 & 1.7213 \\
Skewness & 0.7624 & 1.0639 & 0.8182 \\
Kurtosis & -0.8943 & -0.0072 & 0.9072 \\
Obs. & 790 & 790 & 790 \\
\hline & LARGESP & SMALLSP & SECSP \\
\hline Mean & -3.9930 & 11.1197 & 16.1322 \\
Median & -3.8886 & 12.2074 & 17.1168 \\
Std. Dev. & 3.1385 & 4.5990 & 6.1488 \\
Skewness & -0.0543 & -1.0035 & -0.1506 \\
Kurtosis & -1.3578 & 0.3007 & 0.7422 \\
Obs. & 790 & 790 & 790 \\
\hline
\end{tabular}

Notes. This table exhibits the descriptive statistics of the variables used in this paper for the period from January 4, 2011 to March 20, 2014. In the table, Std. Dev. denotes the standard deviation values and Obs. denotes the number of the observations in our analyzing sample period. 
Table 1 exhibits the descriptive statistics for our seven log index returns and six adjusted index price spreads over TOPIX. Interestingly, this table indicates that JASSP, MOSP, SMALLSP, and SECSP demonstrate the positive price spreads over TOPIX in our full sample period; on the other hand, CORESP and LARGESP exhibit the negative price spreads over TOPIX in the same period.

\section{Models}

In order to examine whether the regime of stock return changed after the inauguration of the new cabinet in Japan, we estimate several two-regime Markov switching models. More specifically, for the daily log return of TOPIX, the model is as follows:

$$
D L T O P I X_{t}=v_{\text {TOPIX }}(k)+\sigma_{\text {TOPIX }}(k) \eta_{t},
$$

where $\eta_{t}$ follows the independent and identically distributed (iid) standard normal distribution. In addition, $v_{\text {TOPIX }}(k)$ denotes the constant term governed by regime $k$, and $\sigma_{\text {TOPIX }}(k)$ means the volatility of DLTOPIX in regime $k(k=1$ or 2$)$.

Further, for the daily log return of JASDAQ Index, the model is as follows:

$$
D L J A S_{t}=v_{J A S D A Q}(k)+\sigma_{J A S D A Q}(k) \zeta_{t},
$$

where $\zeta_{t}$ follows the iid standard normal distribution; $v_{\text {JASDAQ }}(k)$ denotes the constant term in regime $k$, and $\sigma_{\text {JASDAQ }}(k)$ denotes the volatility of DLJAS in regime $k(k=1$ or 2$)$.

Moreover, for the daily log return of the TSE Mothers Index, the model is as follows:

$$
D L M O_{t}=v_{\text {MOTHERS }}(k)+\sigma_{\text {MOTHERS }}(k) \psi_{t},
$$

where $\psi_{t}$ follows the iid standard normal distribution; $v_{\text {MOтнЕRS }}(k)$ is the constant term in regime $k$, and $\sigma_{\text {MOTHERS }}(k)$ denotes the volatility of DLMO in regime $k(k=1$ or 2$)$.

\section{Empirical Results}

In this section, we document our empirical results. We also display the time-series of DLTOPIX, DLJAS, and DLMO in Panels A, B, and C in Figure 2, respectively. Hence in this figure, we can view the time-series characteristics of the three variables, to which the above models are applied. Further, the estimation results of our three models are shown in Table 2, and the probabilities that these variables are in regime 1 or 2 are exhibited in Figure 3.

Explaining the results in short, Table 2 indicates that for all three variables, DLTOPIX, DLJAS, and DLMO, the coefficients of volatilities are higher in regime 2 than in regime 1. Further, constant terms are statistically significant with positive signs in regime 1 for all three models whilst in regime 2 , constant terms are negative for all three models although they are not statistically significant. 
Table 2. Estimation results of the two-regime Markov switching models: the results for the period from January 4, 2011 to March 20, 2014

Panel A. DLTOPIX

\begin{tabular}{|c|c|c|c|}
\hline Variable & Coeff. & SE & $p$-value \\
\hline \multicolumn{4}{|l|}{ Regime 1} \\
\hline Const. & $0.0772 *$ & 0.0424 & 0.0687 \\
\hline $\ln \left(\sigma_{\text {TOPIX }}(1)\right)$ & $0.0944 * * *$ & 0.0302 & 0.0017 \\
\hline \multicolumn{4}{|l|}{ Regime 2} \\
\hline Const. & -0.5387 & 0.4520 & 0.2334 \\
\hline $\ln \left(\sigma_{\text {TOPIX }}(2)\right)$ & $1.1086^{* * *}$ & 0.1128 & 0.0000 \\
\hline \multicolumn{4}{|l|}{ Model statistics } \\
\hline $\mathrm{LL}$ & -1284.409 & AIC & 3.2669 \\
\hline \multicolumn{4}{|l|}{ Panel B. DLJAS } \\
\hline Variable & Coeff. & SE & $p$-value \\
\hline \multicolumn{4}{|l|}{ Regime 1} \\
\hline Const. & $0.1235^{* * *}$ & 0.0304 & 0.0000 \\
\hline $\ln \left(\sigma_{\mathrm{JASDAQ}}(1)\right)$ & $-0.3796 * * *$ & 0.0454 & 0.0000 \\
\hline \multicolumn{4}{|l|}{ Regime 2} \\
\hline Const. & -0.1628 & 0.2012 & 0.4184 \\
\hline $\ln \left(\sigma_{\mathrm{JASDAQ}}(2)\right)$ & $0.8791 * * *$ & 0.0826 & 0.0000 \\
\hline \multicolumn{4}{|l|}{ Model statistics } \\
\hline $\mathrm{LL}$ & -1068.670 & AIC & 2.7207 \\
\hline \multicolumn{4}{|l|}{ Panel C. DLMO } \\
\hline Variable & Coeff. & SE & $p$-value \\
\hline \multicolumn{4}{|l|}{ Regime 1} \\
\hline Const. & $0.2272 * * *$ & 0.0633 & 0.0003 \\
\hline $\ln \left(\sigma_{\text {MOTHERS }}(1)\right)$ & $0.2400 * * *$ & 0.0481 & 0.0000 \\
\hline \multicolumn{4}{|l|}{ Regime 2} \\
\hline Const. & -0.2120 & 0.2216 & 0.3387 \\
\hline $\ln \left(\sigma_{\text {MOTHERS }}(2)\right)$ & $1.3563^{* * *}$ & 0.0558 & 0.0000 \\
\hline \multicolumn{4}{|l|}{ Model statistics } \\
\hline $\mathrm{LL}$ & -1695.666 & AIC & 4.3080 \\
\hline
\end{tabular}

Notes. This table exhibits the estimation results of the two-regime Markov switching models which are applied to the percentage log return of TOPIX, the percentage log return of JASDAQ Index, and the percentage log return of TSE Mothers Index. The results are those for the period from January 4, 2011 to March 20, 2014. In the table, Const. denotes constant terms, Coeff. denotes the coefficient of variable, SE indicates the standard error, LL represents the log likelihood values, and AIC denotes the Akaike information criterion. Further, ${ }^{* *}, * *$, and $*$ denote the statistical significance at the 1,5 , and $10 \%$ levels, respectively. 
Panel A. Log return of TOPIX

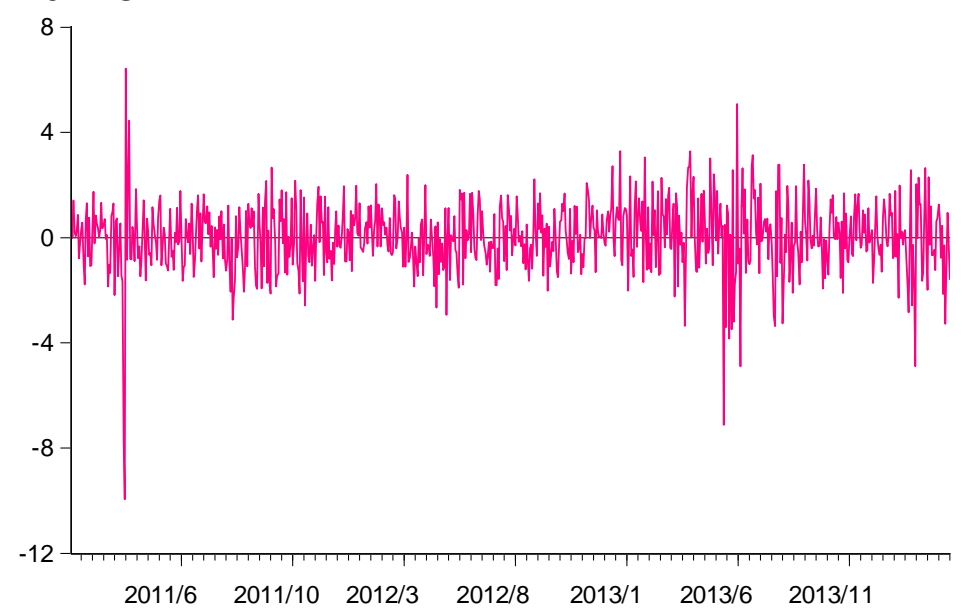

Panel B. Log return of JASDAQ

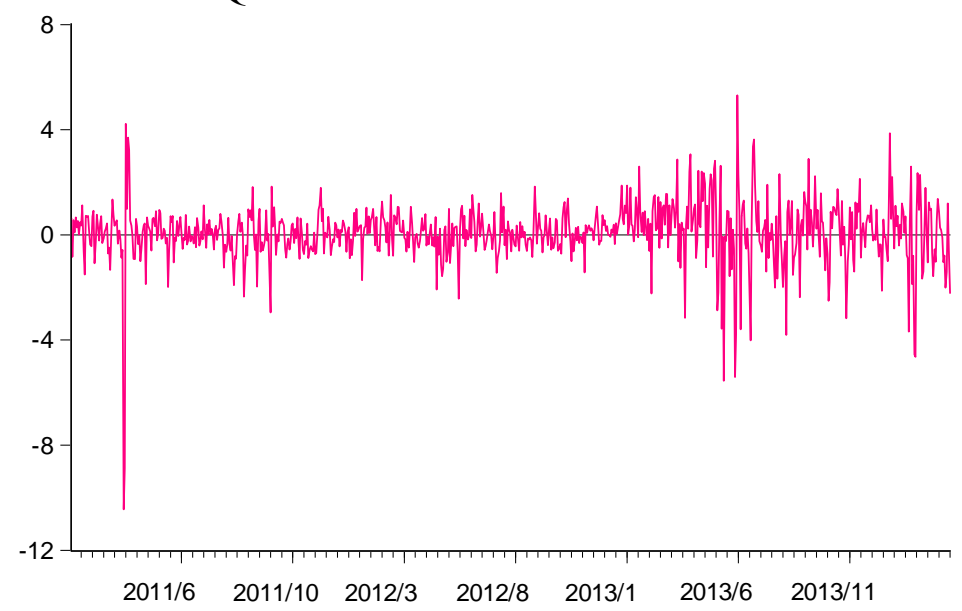

Panel C. Log return of TSE Mothers

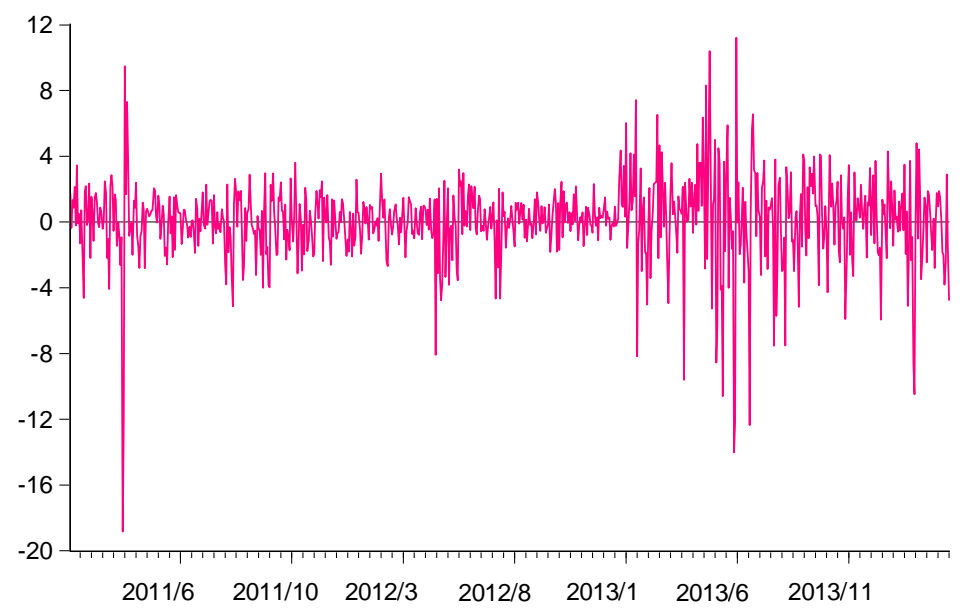

Figure 2. Dynamics of the percentage log return of the Japanese stock indices: time-series evolution for the period from January 4, 2011 to March 20, 2014 
Panel A. Log return of TOPIX

Regime 1

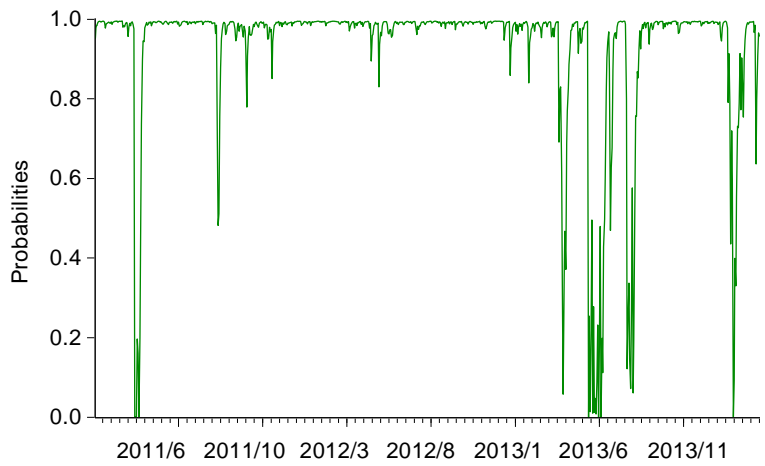

Panel B. Log return of JASDAQ

Regime 1

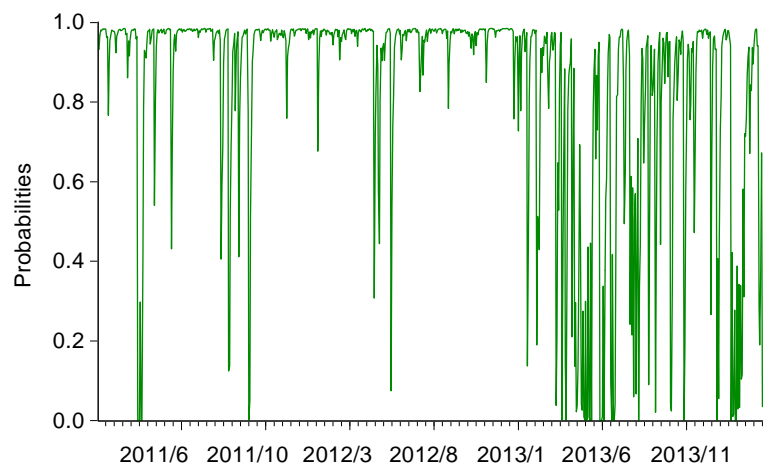

Panel C. Log return of TSE Mothers

Regime 1

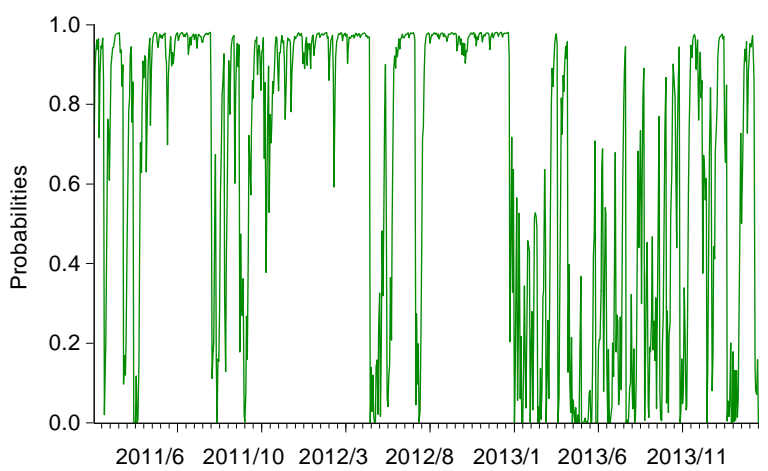

Regime 2

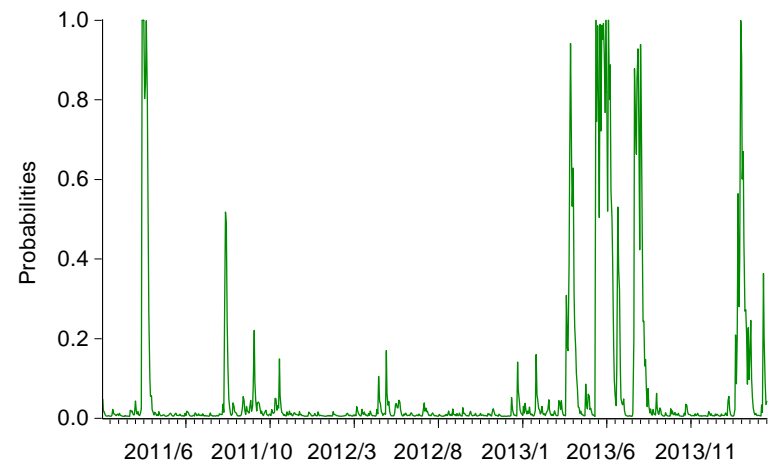

Regime 2

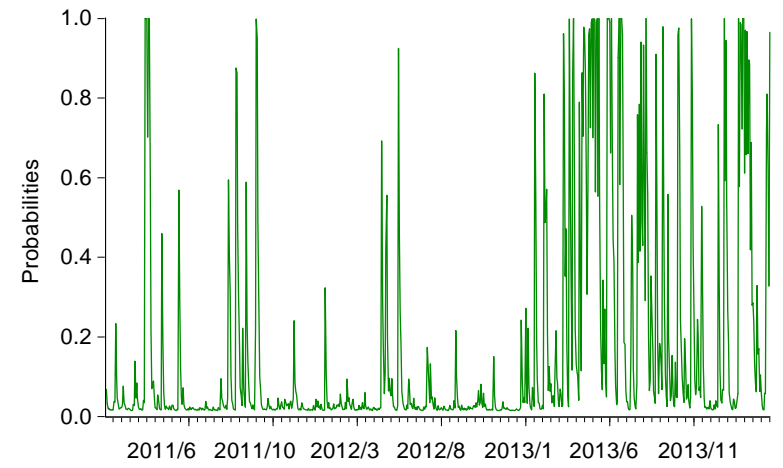

Regime 2

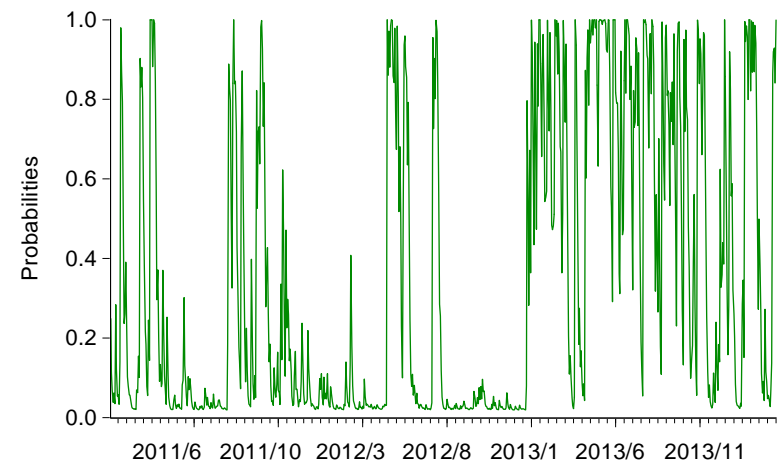

Figure 3. Two regime probabilities derived from Markov switching models: time-series evolution for the period from January 4, 2011 to March 20, 2014 
The tendency in terms of the levels and volatilities for all variables also can be seen graphically in Figure 2; the levels of three variables are slightly negative in average after around May 2013 for DLTOPIX, after around April 2013 for DLJAS, and after around January 2013 for DLMO. Figure 2 also graphically inform us that the volatilities of three variables are relatively higher in average after around May 2013 for DLTOPIX, after around April 2013 for DLJAS, and after around January 2013 for DLMO. Moreover, Figure 3 also suggests that DLJAS stays longer and earlier in higher volatility state, regime 2 than DLTOPIX, and this figure further indicates that DLMO stays in regime 2 with higher probabilities than DLJAS.

Based on the results derived from the estimations of our two-regime Markov switching models, we thus can interpret that the Japanese stock market regime changed to the higher volatility regime after the inauguration of the new Abe cabinet in Japan.

\section{Conclusions}

This paper explored whether the Japanese stock market regime changed after the inauguration of the new cabinet in Japan in December 2012. Our application of Markov switching models to the Japanese stock price index returns and examinations of the price spreads of the Japanese stock price indices revealed the following evidence. First, (1) after the new Abe cabinet started, regime of the Japanese stock markets changed. Second, (2) the regimes of the JASDAQ Index and TSE Mothers Index more strongly and sooner changed than that of TOPIX. Third, (3) in our full sample period from January 4, 2011 to March 20, 2014, average positive stock price spreads were observed with regard to the JASDAQ, TSE Mothers, TOPIX Small, and TSE Second Section Index.

It is not certain that the above favorable stock market trends, in particular, after the new Abe cabinet started continue more in the future; however, it is a fact that, after the inauguration of the new cabinet, the expectation change for the future economy push the Japanese stock market prices up. Hence we should carefully watch not only the trends of the Japanese stock markets and economy but also the monetary policies of Bank of Japan and future policies of the Japanese government.

\section{Acknowledgements}

I am particularly grateful to the kind repeated invitation from the journal to write to this journal. I also thank the Editor and anonymous referees for their kind comments to this paper. Further, I appreciate the Japan society for the promotion of science for their generous financial assistance to this research.

\section{References}

Chen, S. W. (2013). Long memory and regime switching properties of current account deficits in the US. Economic Modelling, 35, 78-87. http://dx.doi.org/10.1016/j.econmod.2013.06.046

Guidolin, M., \& Hyde S. (2012). Simple VARs cannot approximate Markov switching asset allocation decisions: An out-of-sample assessment. Computational Statistics and Data 
Analysis, 56, 3546-3566. http://dx.doi.org/10.1016/j.csda.2010.10.006

Hamilton, J. D. (1989). A new approach to the economic analysis of nonstationary time series and the business cycle. Econometrica, 57, 357-384.

Pan, Q., \& Li, Y. (2013). Testing volatility persistence on Markov switching stochastic volatility models. Economic Modelling, 35, 45-50. http://dx.doi.org/10.1016/j.econmod.2013.06.029

Pardo, S., Rautureau, N., \& Vallée, T. (2011). Optimal versus realized policy rules in a regime-switching framework. Economic Modelling, 28, 2761-2775. http://dx.doi.org/10.1016/j.econmod.2011.07.004

Pataracchia, B. (2011). The spectral representation of Markov switching ARMA models. Economics Letters, 112, 11-15. http://dx.doi.org/10.1016/j.econlet.2011.03.003

Taamouti, A. (2012). Moments of multivariate regime switching with application to risk-return trade-off. Journal of Empirical Finance, 19, 292-308. http://dx.doi.org/10.1016/j.jempfin.2011.12.001

Tamgac, U. (2011). Crisis and self-fulfilling expectations: The Turkish experience in 1994 and 2000-2001. International Review of Economics and Finance, 20, 44-58. http://dx.doi.org/10.1016/j.iref.2010.07.005

Terra, C., \& Valladares, F. (2010). Real exchange rate misalignments. International Review of Economics and Finance, 19, 119-144. http://dx.doi.org/10.1016/j.iref.2009.05.004

Tsuji, C. (2007). What macro-innovation risks really are priced in Japan? Applied Financial Economics, 17, 1085-1099. http://dx.doi.org/10.1080/09603100600749345

Tsuji, C. (2012). Positive return premia in Japan. Quantitative Finance, 12, 345-367. http://dx.doi.org/10.1080/14697688.2010.541485

\section{Copyright Disclaimer}

Copyright reserved by the author(s).

This article is an open-access article distributed under the terms and conditions of the Creative Commons Attribution license (http://creativecommons.org/licenses/by/3.0/). 